Equilibrium : Jurnal Pendidikan

Vol. X. Issu 1. Januari-April 2022
Prodi Pendidikan Sosiologi

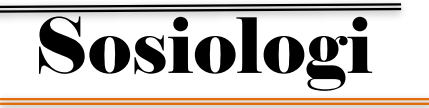

http://journal.unismuh.ac.id/index.php/equilibrium

\title{
Resistensi Mahasiswa Terhadap Pembelajaran Online Pada Masa Pandemi
}

\author{
Saidang ${ }^{1}$ Shermina Oruh ${ }^{2}$ Andi Agustang ${ }^{3}$ \\ ${ }^{1}$ Mahasiswa Program Pascasarjana S3 Sosiologi Universitas Negeri Makassar \\ Email: saidangsaid03@gmail.com \\ ${ }^{2}$ Dosen Universitas Pejuang Republik Indonesia \\ Email: soruh@yahoo.co.id \\ ${ }^{3}$ Dosen Universitas Negeri Makassar \\ Email: andiagust63@gmail.com
}

\begin{abstract}
The Covid-19 pandemic has profoundly changed the structure and function of society. Learning that takes place in schools or colleges that are already familiar with face-to-face learning patterns. The use of internet-based online media is even suspected of causing problems, even during the pandemic it is widely used in the learning process. This study aims to find forms of student resistance to learning during the pandemic. The approach used in this study is a descriptive qualitative approach using case study methods in the Enrekang District, Enrekang District. The results of the study prove that online learning during the pandemic creates a resistant attitude among students. Open resistance is shown by showing refusal or boredom to attend online lectures by inviting other students not to attend lectures. While closed resistance is carried out secretly, namely by not involving other people following their deviant actions. Several factors that influence student resistance include economic factors, natural factors (geography), and the ability to access the internet network.
\end{abstract}

Keywords : Resistance; Online Learning; Pandemic Times

\begin{abstract}
Abstrak. Pandemi covid-19 telah merubah struktur dan fungsi masyarakat secara besar-besaran. Pembelajaran yang berlangsung di sekolah atau perguruan tinggi yang sudah terbiasa dengan pola pembelajaran tatap muka langsung. Penggunaan media online berbasis internet bahkan dicurigai membawa masalah, justru pada masa pandemi banyak digunakan dalam proses pembelajaran. Penelitian ini bertujuan untuk menemukan bentukbentuk resistensi mahasiswa terhadap pembelajaran pada masa pandemi. Pendekatan yang digunakan dalam penelitian ini adalah pendekatan kualitatif deskriptif dengan menggunakan metode studi kasus daerah Kecamatan Enrekang, Kabupaten Enrekang. Hasil penelitian membuktikan bahwa pembelajaran online selama masa pandemic melahirkan sikap resisten di kalangan mahasiswa. Resistensi terbuka ditunjukkan dengan menunjukkan penolakan atau kejenuhan mengikuti kuliah online dengan mengajak mahasiswa lainnya untuk tidak mengikuti perkuliahan. Sedangkan resistensi tertutup dilaksanakan dengan cara diam-diam yakni dengan tidak melibatkan orang lain mengikuti tindakannya yang menyimpang. Beberapa faktor yang mempengaruhi resistensi mahasiswa tersebut antara lain karena faktor ekonomi, faktor alam (geografi) dan faktor kemampuan mengakses jaringan internet.
\end{abstract}

Kata Kunci : Resistensi; Pembelajaran Online; Masa Pandemi 


\section{PENDAHULUAN}

Pembelajaran pada masa pandemi melahirkan tindakan perlawanan atau resistensi mahasiswa terhadap proses belajar. Mahasiswa menunjukkan sikap yang tidak akomodatif terhadap proses belajar dengan konsep baru belajar berbasis jaringan atau juga disebut belajar daring (dalam jaringan) atau belajar online. Mereka mengikuti perkuliahan berbasis jaringan internet dari tempat yang berbeda di kota maupun di pelosok desa. Khusus mahasiswa di Kabupaten Enrekang mengikuti proses perkuliahan pada titik-titik tertentu yang ditempat tersebut mereka mendapatkan signal internel. Komunikasi dosen dan mahasiswa sebatas tatap muka dalam jaringan sehingga ikatan emosional dosen dengan mahasiswa berkurang (Febriani, 2021). Belajar pada masa pandemi menggambarkan kondisi shock culture dengan kebiasaan baru belajar online (Sri kuning, 2021)(Muttaqin et al., 2021)(Maisaroh \& Ali, 2021). Bagi yang kesulitan mendapatkan jaringan internet di rumahnya, mereka mencari titik tertentu untuk mendapatkan jaringan. Mahasiswa mengikuti proses perkuliahan di rumah maupun ditempat-tempat yang terjangkau jaringan internet baik di rumah maupun diluar rumah. Sulitnya mendapatkan jaringan di daerah pelosok dan pegunungan sehingga sering mahasiswa atau siswa tidak hadir dalam perkuliahan.

Penelitian tentang pembelajaran online atau pembelajaran dalam jaringan menemukan bahwa pembelajaran dengan tatap muka langsung masih lebih baik (Wiley \& Hilton III, 2018). Justru mahasiswa mengalami tekanan atau stess dengan pembelajaran online (Maulana \& Iswari, 2020). Kendala-kendala dalam pembelajaran online berkaitan dengan faktor ekonomi karena kebutuhan biaya yang banyak sehingga dianggap bahwa pembelajaran online kurang efektif (Agus Susilo, 2013) dan bertambahnya biaya pengeluaran di tingkat keluarga mahasiswa (Setiani, 2021). Selama masa pandemi, pembelajaran dengan sistem online menyebabkan kejenuhan peserta didik (mahasiswa) (Fitriasari et al., 2020). Beberapa faktor yang mempengaruhi berkaitan dengan keengganan intelektual, perubahan dan dukungan teknis (Mitchell et al., 2009). Faktor lain seperti kondisi geografis juga mempengaruhi proses pembelajaran online (Palinggi, 2020). Menghadapi resistensi pembelajaran online ini, maka harus ada inovatif dalam pembelajaran untuk menghindari kebosanan atau resistensi mahasiswa sehingga tercipta pembelajaran efektif (Fanani \& Jainurakhma, 2020). Dari beberapa penelitian tentang resistensi mahasiswa terhadap pembelajaran selama masa pandemi, belum ditemukan bentuk resistensi mahasiswa terhadap pembelajaran khususnya untuk mahasiswa yang tinggal di desa-desa atau pelosok. Oleh karena itu, penelitian bertujuan untuk menemukan bentuk adaptasi mahasiswa terhadap pembelajaran pada masa pandemi. Sebagian dari sikap dan tindakan tersebut adalah berbentuk resistensi terhadap pembelajaran online.

Penelitian ini penting dilaksanakan untuk menjamin bahwa pembelajaran online dapat dilaksanakan meskipun di luar masa pandemi. Pada era baru (new normal) pembelajaran online akan tetap diselenggarakan mengingat ada dampak positif dari proses pembelajaran yang dinilai efektif di masa pandemi. Penelitian ini menemukan bahwa pembelajaran online dapat diselenggarakan di daerah-daerah pelosok atau pedesaan dengan meminimalisir faktor-faktor yang menghambat proses pembelajaran online. Oleh karena itu, penelitian ini bertujuan mengkaji tentang resistensi mahasiswa terhadap pembelajaran selama masa pandemi. Bagaimana faktor-faktor sosial mempengaruhi proses resistensi mahasiswa terhadap pembelajaran online selama pandemi.

Lingkungan sosial memberikan pengaruh terhadap resistensi mahasiswa dalam merespon proses pembelajaran. Resistensi tersebut lahir dari sosialisasi dengan lingkungan sosial utamanya dari lingkungan keluarga mahasiswa, lingkungan sekolah dan teman sejawat (Tsabar, 2014)(Scott, 2020). Dalam proses belajar, mahasiswa beradaptasi dengan lingkungan pendidikan (Tangkudung, 2014). Proses sosialisasi mahasiswa dengan teman sejawat, lingkungan kampus, dan media sosial memberi kontribusi terhadap perkembangan kognitif, afektif dan psikomotoriknya (Trisnawati et al., 
2021). Pengaruh lingkungan membentuk kebiasaan baru mahasiswa dalam hal bertindak dan bertutur kata.

Proses sosialisasi yang berlangsung secara terus menerus dalam lingkungan melalui proses dialektis dari proses ekternalisasi, objektivasi sampai kepada internalisasi (Poloma, 2003)(Dharma, 2018). Proses tersebut diawali dengan tawar menawar individu untuk bisa beradaptasi dengan lingkungannya. Selanjutnya adalah proses pelembagaan diri terhadap kebiasaan baru. Proses sosialisasi yang panjang kemudian membentuk kebiasaan atau habitus. Sifat dasar mahasiswa yang senang mencoba hal-hal baru menarik minat mahasiswa untuk melakukannya (David et al., 2014)(Zakiah et al., 2020). Ketika lingkungannya memberikan penghargaan terhadap prilaku yang baru tersebut maka semakin mengokohkan prinsip untuk melakukan tindakan berulang-ulang sehingga lama kelamaan terbentuk kebiasaan baru. Sosialisasi formal yang berlangsung dalam lingkungan pendidikan mahasiswa saling memberi pengaruh terhadap pola dan kebiasaan merespon lingkungan pergaulan di masyarakat, teman sejawat, sahabat dan kelompok sosial lainnya.

Interaksi dosen dengan mahasiswa dapat berupa interaksi asosiatif dan juga disosiatif (Rijal, 2021)(Hajiah \& Amri, 2018). Interaksi asosiatif terwujud dalam bentuk saling bekerjasama, saling memahami, rukun dan damai (Lamanepa et al., 2016). Sikap senang ketika bertemu satu dengan yang lain merupakan aktualisasi dari nilai-nilai interaksi asosiatif. Dalam kuliah online tindakan dosen dan mahasiswa yang tenang, dosen menyampaikan materi dengan nyaman karena mahasiswa cukup perhatian, dosen juga cukup menyimak komentar dan pendapat mahasiswa dengan penuh perasaan adalah bentuk interaksi asosiatif (Iskandar et al., 2019). Kebalikannya dengan interaksi disosiatif yang menggambarkan hubungan negatif yang saling merugikan kedua belah pihak. Penyimpangan yang dilakukan dapat terwujud dalam bentuk ucapan maupun tindakan. Dosen yang kurang baik akan memperlihatkan sikap dan prilaku yang kurang akpmodatif dengan mahasiswa. Penyebabnya bisa bermacam-macam misalnya karena kesalahpahaman dosen dan mahasiswa dan berpotensi melahirkan pelawanan atau resistensi dalam proses pembelajaran (Maulana \& Iswari, 2020). Dalam pembelajaran online, banyak hal yang dapat menyebabkan lahirnya persepsi yang keliru dalam interaksi (Argaheni, 2020). Pengaruh pada kemampuan memahami materi pelajaran, pengaruh sosial, ekonomi dan lain-lain.

\section{METODE PENELITIAN}

Penelitian ini menggunakan pendekatan kualitatif deskriptif, studi kasus gerakan mahasiswa. Penelitian ini dilakukan terhadap mahasiswa Universitas Muhammadiyah Enrekang yang umumnya terdiri dari mahasiswa yang berdomisili dalam wilayah Kabupaten Enrekang. Rata-rata mahasiswa tinggal di desa-desa sampai ke pelosok kampung dan pegunungan sebagaimana kondisi topografi Kabupaten Enrekang. Data yang dibutuhkan dalam penelitian ini diperoleh melalui dua sumber data yaitu sumber primer yaitu langsung kepada mahasiswa dan data sekunder yaitu sumber-sumber berita online dan pemberitaan media cetak lainnya. Teknik pengumpulan data melalui wawancara mendalam dengan informan dan observasi. Wawancara dilaksanakan dengan cara menanyakan langsung kepada mahasiswa dan dengan membuat forum group diskusi (FGD) dan juga dengan mengirimkan instrument penelitian secara online.

Data yang diperoleh melalui wawancara dan observasi kemudian direduksi dengan memilih berdasarkan tema-tema yang berkaitan dengan resistensi mahasiswa, kemudian dibuatkan sbstrak untuk menyederhanakan pembahasan sehingga diperoleh data tentang prilaku atau respon mahasiswa terhadap pembelajaran online. Data yang terkumpul melalui dibuatkan display untuk mengkategorikan data yang diperoleh dan menguatkan bukti-bukti yang diteliti. 


\section{HASIL PENELITIAN DAN PEMBAHASAN}

\section{A. Hasil Penelitian}

Proses belajar online atau daring (dalam jaringan) pada masa pandemi menjadi hambatan terhadap berlangsungnya belajar yang efektif. Kebiasaan belajar dengan cara bertatap muka langsung dianggap telah berhasil membawa perubahan. Pada masa pandemi suasana belajar online tidak mampu mengontrol perilaku peserta didik sehingga ukuran keberhasilan pendidik mengubah prilaku tidak dapat diukur. Penyimpangan-penyimpangan perilaku dalam pembelajaran sulit dipantau karena pembelajaran yang berjarak dan pemantauan yang sangat sulit disebabkan oleh komunikasi yang dibatasi oleh layar atau monitor media komunikasi yang digunakan. Bentuk perlawanan atau penolakan mahasiswa terhadap proses pembelajaran pada masa pandemi ditunjukkan dengan cara terbuka dan tertutup. Perlawanan terbuka dilakukan melalui cara-cara munjukkan ketidak senangan dengan mengajak orang banyak atau teman-temannya untuk sepakat tidak menghadiri perkuliahan dengan mencari alasan atau bersama untuk tidak hadir dalam perkuliahan online.

Penelitian terhadap pembelajaran mahasiswa Universitas Muhammadiyah Enrekang pada masa pandemi menemukan beberapa faktor yang mempengaruhi proses belajar. Proses pembelajaran menggunakan standar protokol kesehatan yakni belajar di rumah kecuali untuk mata kuliah praktek tetap pembelajaran tatap muka dengan menerapkan protokol kesehatan. Ternyata bahwa mahasiswa yang tinggal di daerah pegunungan seperti Enrekang tidak terlalu memperhatikan protokol kesehatan. Sebagian mahasiswa yang orang tuanya adalah petani pada masa pendemi ini justru semakin banyak waktunya bersama orang tua di kebun atau sawah milik orang tua.

Ciri khas Wilayah Kabupaten Enrekang yang sebagian besar terdiri dari daerah pegunungan dimana tidak semua daerah dapat dijangkau jaringan internet dengan baik. Khusus wilayah luar ibu kota Kabupaten Enrekang juga tidak dijangkau jaringan Telkom sehingga akses internet satu-satunya adalah jaringan nirkabel. Sebagian besar mahasiswa yang tinggal di desa-desa sering mengalami gangguan jaringan menyebabkan mereka tidak mampu mengakses proses belajar dengan baik. Kondisi topografi alam yang bergunung-gunung berpengaruh kepada jaringan internet . Pada saat mendung atau hujan yang sering terjadi di daerah pegunungan, proses belajar sering terkendala jaringan sehingga mahasiswa yang tinggal di daerah pegunungan kurang maksimal mengikuti perkuliahan. Faktor biaya pembelian data internet juga sangat mempengaruhi atau menambah belanja karena mahal. Orang tua dan mahasiswa banyak mengeluhkan kuliah harus dengan paket data yang banyak.

Pada masa pandemi dimana perkuliahan secara daring berlangsung di mana saja. Dengan penerapan kebiasaan baru belajar online ternyata tidak merubah kebiasaan lama masyarakat. Penelitian ini menemukan bahwa mahasiswa yang berlatar belakang keluarga petani dengan kebiasaan bekerja di kebun. Bagi mahasiswa yang orang tuanya petani, kebiasaannya berkaitan dengan kecenderungan bertani demikian juga dengan mereka dari keluarga pedagang atau usaha kecil lainnya, tetap dengan kebiasaan-kebiasaan lama. Seluruh kebiasaan tersebut tidak lahir begitu saja tetapi terbentuk oleh pengalaman yang sudah menstruktur pikiran dan masyarakat. Belajar pada masa pandemi dengan cara online sebagai bentuk pembeiasaan baru (new normal) memakan waktu yang relatif lama karena menghadapi kultur masyarakat.

Berbagai bentuk tindakan mahasiswa dalam pembelajaran yang menunjukkan resistensi terbuka dan tertutup. Bentuk tindakan terbuka dilakukan dengan melibatkan banyak orang atau teman-temannya. Beberapa mahasiswa yang sering tidak hadir kuliah karena alasan kuliah online memberatkan karena paket data yang mahal, ada juga karena daerah mereka sulit mendapatkan jaringan internet. Dikampung-kampung tidak semua tempat mendapatkan jaringan internet sehingga mereka mencari titik-titik tertentu untuk mendapatkan signal jaringan internet. Tempat atau titik 
tertentu tersebut kadang-kadang letaknya di luar kampung. Dengan kondisi demikian, mahasiswa kadang-kadang tidak hadir dalam perkuliahan. Bahkan ada yang mengajak temannya untuk tidak hadir dalam perkuliahan. Cara belajar berbasis online yang sering mengalami gannguan menyebabkannya tidak bisa menangkap materi pembelajaran dengan utuh.

Resistensi tertutup mahasiswa terhadap pembelajaran online ditunjukkan dengan kepurapuraan patuh kepada dosen. Pada saat mereka ditagih tentang tugas, ada saja alasanya sehingga tugas tidak jadi dikumpulkan. Beberapa mahasiswa dalam penelitian ini mengaku bahwa tidak mengumpulkan tugasnya. Terdapat juga mahasiswa yang mengumpulkan tugasnya dengan memplagiasi milik temannya atau mencari jawaban di Google tanpa melakukan proses editing.

\section{b. Pembahasan}

Dampak yang mahasiswa rasakan dari pembelajaran online adalah proses belajar tidak efektif karena alasan teknis dan strategis. Secara teknis perkuliahan pada masa pandemi mengalami berbagai kendala karena kuliah dengan online membutuhkan media komunikasi yang mendukung misalnya minimal HP android dengan spesifikasi khusus atau laptop yang memiliki spesifikasi yang mendukung pembelajaran online. Fasilitas listrik juga harus mendukung terjadinya proses pembelajaran. Di pedesaan-pedesaan daerah ini seringkali lampu padam dalam jangka waktu yang lama sehingga tidak mendukung proses pembelajaran yang efektif. Kendala teknis lain seperti harus memiliki paket data sering menjadi kendala utama proses belajar online. Secara strategis pembelajaran online memudahkan banyak orang tergabung mengikuti proses pembelajaran. Alasannya adalah karena belajar online dapat diikuti siapa dan dimana saja. Banyak pihak yang merasa diuntungkan karena perkuliahan secara online sebenarnya sangat menghemat biaya dimana peserta didik atau para mahasiswa tidak mengeluarkan biaya banyak untuk harus hadir dalam ruang kelas.

Resistensi mahasiswa pada peroses belajar secara online menunjukkan bahwa proses pembelajaran yang efektif tidak terjadi(Simatupang et al., 2020)(Herliandry et al., 2020)(Hapsari \& Pamungkas, 2019). Beberapa aplikasi seperti zoom, google classroom, dan lain-lain membutuhkan paket data yang banyak. Kuliah zoom misalnya dalam satu kali pertemuan saja sudah menggunakan kuota internet yang tidak sedikit. Sehingga apabila semua mata kuliah menggunakan data internet, tentu sangat memberatkan mahasiswa. Kondisi yang memberatkan mahasiswa tersebut memunculnya ketidak nyamanan mengikuti perkuliahan.

Asumsi bahwa pembelajaran online melahirkan perlawanan atau resistensi mahasiswa merespon perkuliahan selama masa pandemi. Resistensi mahasiswa tersebut ditunjukkan dengan cara mempengaruhi teman sendiri sesama mahasiswa secara subjektif. Berbagai tindakan yang dilakukan pada dasarnya tidak menggambarkan bahwa terjadi mahasiswa menolak secara keseluruhan perkuliahan online (Savira et al., 2021). Beberapa faktor lain juga ditemukan berhubungan dengan faktor-faktor sosial dan teknis. Faktor tekis yang juga mempengaruhi dosen dan mahasiswa adalah gap teknologi. Dosen dan mahasiswa ternyata banyak yang tidak siap dengan metode baru pembelajaran online (Mulawarman, 2020)(Komang \& Astini, 2020). Ada dosen yang otoriter, kurang tegas, diskriminatif dan sebagainya dalam memperlakukan mahasiswa. Bentuk resistensi lain mahasiswa terhadap proses pembelajaran adalah dengan diam-diam atau sembunyisembunyi atau tidak menampakkannya dalam bentuk tindakan yang mempengaruhi orang lain. Sebaliknya perlawanan terbuka dilakukan dengan memperlihatkan atau dengan mengajak temannya untuk menolak atau tidak hadir dalam pertemuan di kelas bersama dengan dosen.

Pembelajaran online yang berlangsung selama pandemi menghasilkan berbagai bentuk perlawanan atau resistensi terhadap proses pembelajaran. Penelitian ini menemukan bahwa resistensi mahasiswa tersebut selain berhubungan dengan pelayanan atau pola interaksi dosen 
dengan mahasiswa. Beberapa faktor yang mempengaruhi antara lain faktor ekonomi, faktor georafi dan faktor sosial. Faktor ekonomi berkaitan dengan biaya karena pada masa pandemi tekanan ekonomi bertambah oleh pembatasan kegiatan masyarakat yang berdampak kepada pendapatan. Perkuliahan pada masa pandemi yang membutuhkan media dan akan mempengaruhi belanja rumah tangga. Faktor geografi juga ternyata memberikan pengaruh terhadap pembelajaran online. Wilayah Kabupaten Enrekang khususnya yang sebagian besar adalah wilayah pegunungan menyebabkan jaringan internet tidak merata bisa diterima baik sehingga menjadi salah satu penghambat pembelajaran online.

Penelitian ini menemukan bahwa kendala teknis pembelajaran online yang digambarkan sebagai sebuah ketimpangan sosial. Daerah ibu kota Kabupaten bisa mengakses dengan mudah proses pembelajaran online karena didukung sarana komunikasi berbasis jaringan internet dan jaringan Telkom indihome. Sementara daerah-daerah kecamatan yang berada dibalik gunung dan menyebar di beberapa tempat sangat sulit mengakses internet sehingga mahasiswa di wilayah tersebut terkendala oleh perbedaan fasilitas antar wilayah. Kondisi seperti ini menyebabkan anakanak mahasiswa bahkan para pelajar khususnya di desa-desa merasakan ketimpangan-ketimpangan sosial dengan model pembelajaran online ini.

Pembelajaran online berpengaruh terhadap perubahan ke arah normal baru. Salah satu dampak positif dari sistem pembelajaran online ini adalah terintegrasinya dua sistem pembelajaran ini sebagai sistem yang saling mendukung. Oleh karena itu, pembelajaran online selama masa pandemi menempa sistem pembelajaran menjadi lebih baik. Semantara dampak negatifnya adalah resistensi mahasiswa terhadap proses belajar online. Meskipun tidak berhasil keseluruhan tetapi beberapa aspek teknis dan strategis pembelajaran online membawa perubahan ke arah yang lebih baik. Pandangan negatif tentang pembelajaran online sebelumnya dianggap mendatangkan masalah karena adanya kecurigaan-kecurigaan dan dianggap merugikan peserta didik dalam proses pembelajaran.

\section{KESIMPULAN}

Penelitian ini menemukan bahwa resistensi mahasiswa dalam pembelajaran pada masa pandemi terjadi secara terbuka dan secara tertutup. Bentuk ketidak senangan atau resistensi mahasiswa ini ditunjukkan secara terang-terangan dengan mempengaruhi orang sekitarnya dalam hal ini sesama mahasiswa. Sikap mahasiswa yang resisten tersebut salah satu disebabkan oleh karena interaksi dengan dosen yang tidak intens. Kebiasaan lama berinteraksi secara langsung telah menjadi habitus dan sangat sulit dihilangkan. Kalaupun dipaksakan, membutuhkan proses adaptasi kebiasaan baru yang relatif lama. Peran-peran sosial komponen dalam masyarakat termasuk mahasiswa ikut membentuk perubahan. Oleh karena itu perlawanan atau resistensi terhadap pembelajaran selama pandemi juga disebabkan ketidak mampuan mengakses perubahan yang tibatiba. Masyarakat, sekolah, pelajar dan mahasiswa mengalami shock dengan perubahan yang tibatiba. Sementara kemampuan dan kapasitas yang dimiliki tidak mampu mengakses perubahan tersebut terbatas.

Prilaku mahasiswa terhadap pembelajaran online menggunakan pendekatan teori resistensi menemukan gejala perlawanan yang dinampakkan dan juga ada yang dilakukan secara sembunyisembunyi. Data diperoleh melalui wawancara dengan mahasiswa. Salah satu kekurangan pembelajaran online beraitan dengan kondisi geografis seperti ini adalah akses yang tidak seimbang terhadap pembelajaran online. Penelitian ini menemukan bahwa terjadi ketimpangan dan ketidak adilan pembelajaran online karena sebagian mahasiswa di daerah pelosok sulit menjangkau informasi atau perkuliahan online. 
Keterbatasan penelitian resistensi mahasiswa yang tinggal di daerah-daerah pelosok atau pegunungan resistennya terhadap pembelajaran online. Sikap dan prilaku resistensi tersebut juga dipengaruhi oleh faktor-faktor sosial ekonomi dan georgrafis. Selanjutnya untuk penelitian lanjutan yang penting adalah kajian tentang ketimpangan sosial pembelajaran online sekolah dasar dan menengah pelosok. Pentingnya penelitian lanjutan ini adalah karena negara menjamin setiap warga negara berhak mendapatkan pendidikan. Penelitian ini juga penting karena sistem ujian atau tes nasional pada umumnya menggunakan standar yang sama maka sangat timpang ketika ujian diperlakukan sama pada daerah yang mengalami ketimpangan sosial.

\section{DAFTAR PUSTAKA}

Agus Susilo, F. (2013). Peningkatan Efektivitas Pada Proses Pembelajaran. MATHEdunesa, 2(1).

Argaheni, N. B. (2020). Sistematik Review: Dampak Perkuliahan Daring Saat Pandemi COVID-19 Terhadap Mahasiswa Indonesia. PLACENTUM: Jurnal IImiah Kesehatan Dan Aplikasinya, 8(2), 99. https://doi.org/10.20961/placentum.v8i2.43008

David, L. E. V., Matulessy, A., \& Pratikto, H. (2014). Pola Asuh Demokratis, Kemandirian dan Motivasi Berprestasi pada Mahasiswa. Persona:Jurnal Psikologi Indonesia, 3(01), 65-70. https://doi.org/10.30996/persona.v3i01.370

Dharma, F. A. (2018). konstruksi realitas sosial.pdf. Kanal: Jurnal Ilmu Komunikasi, 7(1). https://doi.org/10.21070/kanal.v\%vi\%i.3024

Fanani, Q., \& Jainurakhma, J. (2020). kemampuan penyesuaian diri mahasiswa.pdf. Jurnal KomtekInfo, 7(4), 285.

Febriani, A. (2021). Proses Komunikas I Informatif Antara Dosen Dan Mahasiswa Di Masa Pandemi Covid-19 Fakultas Ushuluddin Adab Dan Dakwah. Skripsi.

Fitriasari, A., Septianingrum, Y., \& Budury, S. (2020). Stres Pembelajaran Online Berhubungan Dengan Strategi Koping Mahasiswa Selama Pandemi Covid-19. Jurnal Keperawatan, 12(4), 985992.

Hajiah, \& Amri, A. (2018). Pola Interaksi Sosial Mahasiswa Luar Aceh dan Mahasiswa Aceh di Fakultas Ilmu Sosial dan Ilmu Politik Universitas Syiah Kuala. Jurnal IImiah Mahasiswa FISIP Unsyiah, 3(1). http://www.jim.unsyiah.ac.id/FISIP/article/view/6170/2748

Hapsari, S. A., \& Pamungkas, H. (2019). Pemanfaatan google classroom sebagai media pembelajaran online di universitas dian nuswantoro. WACANA, 18(2), 225-233.

Herliandry, L. D., Nurhasanah, N., Suban, M. E., \& Kuswanto, H. (2020). Pembelajaran Pada Masa Pandemi Covid-19. JTP - Jurnal Teknologi Pendidikan, 22(1), 65-70. https://doi.org/10.21009/jtp.v22i1.15286

Iskandar, A. M., Zainuddin, R., Makassar, U. M., \& Bosowa, U. (2019). Interaksi dan Komunikasi Dosen dan Mahasiswa dalam Proses Pendidikan. Jurnal Dakwah Dan Sosial Keagamaan, 5(1).

Komang, N., \& Astini, S. (2020). Tantangan Dan Peluang Pemanfaatan Teknologi Informasi Dalam Pembelajaran Online Masa Covid-19. 3(2), 241-255.

Lamanepa, A., Budjang, G., \& Salim, I. (2016). Interaksi Sosial Antar Mahasiswi Asrama Putri Kabupaten Kapuas Hulu di Kota Pontianak. Jurnal Penddikan Dan Pembelajaran Khatulistiwa, 5(7), 1-13.

https://jurnal.untan.ac.id/index.php/jpdpb/article/view/15983/13927

Maisaroh, S., \& Ali, M. (2021). Culture Shock Dosen Bahasa Arab di Masa Pandemi Covid-19. Al Qodiri: Jurnal Pendidikan, Sosial Dan Keagamaan, 19(2), 5-24.

Maulana, H. A., \& Iswari, R. D. (2020). Analisis Tingkat Stres Mahasiswa Terhadap Pembelajaran Daring Pada Mata Kuliah Statistik Bisnis Di Pendidikan Vokasi. Khazanah Pendidikan, 14(1), 17- 
30. https://doi.org/10.30595/jkp.v14i1.8479

Mitchell, B., May, I., \& Geva. (2009). Attitudes student.pdf. JOURNAL OF DIST ANCE EDUCA TION REVUE DE L'ÉDUCA TION À DIST AN, 23(1), 71-88.

http://www.ijede.ca/index.php/jde/article/view/43/825

Mulawarman, W. G. (2020). Persoalan Dosen dan Mahasiswa Masa Pandemik Covid 19: Dari Gagap Teknologi Hingga Mengeluh Boros Paket Data. Prosiding Seminar Nasional Hardiknas, 1, 37-46. http://proceedings.ideaspublishing.co.id/index.php/hardiknas/article/view/6

Muttaqin, M., Idris, U., KFrank, S., Ilham, I., Akhmad, A., \& Tibul, S. (2021). Cultural Shock of College Students on Facing Online Learning System During Pandemic Covid-19 in Papua. March 2020. https://doi.org/10.4108/eai.25-11-2020.2306700

Palinggi, S. (2020). Efektivitas Pembelajaran Daring Mahasiswa PGSD di Universitas Kristen Indonesia Toraja Selama. SEMINAR NASIONAL : Kualitas Sumberdaya Manusia (KUSUMA).

Poloma, M. M. (2003). Sosiologi Kontemporer. PT. Raja Grafindo Perkasa.

Rijal, S. (2021). Nuansa Edukasi Islami Interaksi Sosial Dosen Dan Mahasiswa. Journal of Education Science, 6(2). http://jurnal.uui.ac.id/index.php/jes/article/view/1166

Savira, L. A., Setiawati, O. R., Husna, I., \& Pramesti, W. (2021). Hubungan Stres dengan Motivasi Belajar Mahasiswa disaat Pandemi Covid-19. Jurnal Ilmiah Kesehatan Sandi Husada, 10(1), 183188. https://doi.org/10.35816/jiskh.v10i1.577

Scott, J. C. (2020). Senjatanya orang-orang yang kalah bentuk-bentuk perlawanan sehari-hari kaum tani. Yayasan Obor Indonesia.

Setiani, H. dkk. (2021). Faktor Penghambat Maharah.

Simatupang, N., Sitohang, S., Situmorang, A., \& Simatupang, I. (2020). Efektivitas Pelaksanaan Pengajaran Online Pada Masa Pandemi Covid-19 Dengan Metode Survey Sederhana. Jurnal Dinamika Pendidikan, 13(2), 197-203.

Sri kuning, D. (2021). Culture Shock: Online Learning in the Covid-19 Pandemic Phase. Jurnal Humaniora Dan Ilmu Pendidikan, 1(1), 55-62

https://doi.org/10.35912/jahidik.v1i1.357

Tangkudung, J. P. M. (2014). Proses Adaptasi Menurut Jenis Kelamin dalam Menunjang Studi Mahasiswa FISIP UNSRAT. Acta Diurna, III(4), 1-11.

Trisnawati, R., Noormawanti, \& Sarbini. (2021). Peran Guru Pendidikan Agama Islam dalam Mengatasi Pengaruh Media Sosial (Studi Kasus SMP Negeri 1 Bumi Ratu Nuban). PROFETIK: Jurnal Mahasiswa Pendidikan Agama Islam, 1(2). https://www.scholar.ummetro.ac.id/index.php/profetik/article/view/1490/639

Tsabar, B. (2014). Resistance and imperfection as educational work: Going against the "harmony" of individualistic ideology. Other Education: The Journal of Educational Alternatives, 3(1), 23-40.

Wiley, D., \& Hilton III, J. L. (2018). International Review of Research in Open and Distributed Learning. International Review of Research in Open and Distributed Learning, 32(3), 83-93.

Zakiah, N. E., Fatimah, A. T., \& Sunaryo, Y. (2020). Implementasi Project-Based Learning Untuk Mengeksplorasi Kreativitas Dan Kemampuan Berpikir Kreatif Matematis Mahasiswa. Teorema: Teori Dan Riset Matematika, 5(2), 286. https://doi.org/10.25157/teorema.v5i2.4194 